\title{
Uso da nanotecnologia no reparo das lesões traumáticas de nervos
}

\author{
Roberto S. Martins ${ }^{1}$, Mario G. Siqueira² \\ Hospital das Clinicas da Faculdade de Medicina da Universidade de São Paulo (HC-FMUSP), SP, Brasil
}

Hospital Santa Marcelina, São Paulo, SP, Brasil

\section{RESUMO}

A nanotecnologia tem permitido avanços revolucionários nos últimos anos em diversas áreas da Ciência, incluindo a medicina, onde o impacto de novas aquisições se faz presente também na neurocirurgia. Trabalhos experimentais têm demonstrado diversas possibilidades do uso de artefatos obtidos a partir da nanotecnologia no tratamento das lesões traumáticas de nervos periféricos. Isto inclui desde a construção de dispositivos semi-sintéticos que substituem a estrutura de um nervo até a manipulação direta dos axônios. O objetivo deste estudo é apresentar ao neurocirurgião uma revisão sobre as principais técnicas de manufatura de nanomateriais e suas aplicações atuais e futuras no manejo das patologias traumáticas dos nervos periféricos.

\section{PALAVRAS-CHAVE}

Nanotecnologia. Lesão de nervo periférico. Regeneração nervosa. Nanomedicina.

\section{ABSTRACT}

Nanotechnology and repair of peripheral nerve injuries.

Over the last several years, nanotechnology has made possible revolutionary advances in several areas of Science, including medicine, where the impact of new acquisitions also has occurred in neurosurgery. Experimental researchs have demonstrated several possibilities for the treatment of peripheral nerve traumatic lesions with artefacts obtained from nanotechnology. This have included the construction of semi-synthetic devices that replace the structure of the nerve and the direct manipulation of axons. The goal of this study is to present a review to the neurosurgeon about nanomaterials manufacture techniques and its current and future applications in peripheral nerve injury.

\section{KEY-WORDS}

Nanotechnology. Peripheral nerve injury. Nerve regeneration. Nanomedicine.

\section{Introdução}

A nanotecnologia pode ser definida como um conjunto de técnicas que possibilita a manipulação de moléculas ou átomos para o desenvolvimento de novos materiais e para a manufatura de artefatos em escala nanométrica ${ }^{13,22}$. Este tipo de processamento é realizado numa escala um bilhão de vezes menor que o metro ou um milhão de vezes menor que o milímetro. Um nanômetro tem o comprimento de 10 átomos de hidrogênio alinhados, enquanto a molécula de ácido desoxirribonucléico (DNA) tem cerca de 2,5 nanômetros (nm) de extensão ${ }^{1,33}$. Essas dimensões muitas vezes são difíceis de imaginar, mas podem ser inferidas a partir de uma simples comparação. Se considerarmos uma praia com 2.000 kilômetros de extensão, as dimensões de um grão de areia estão para o comprimento dessa praia assim como um nanômetro está para o metro ${ }^{7}$.

Na medicina, diversas são as aplicações possíveis da nanotecnologia, principalmente na constituição de novos medicamentos e sua oferta direcionada especificamente às células tumorais ou lesadas, com conseqüente redução dos seus efeitos colaterais. As lesões de nervos periféricos, por apresentarem um potencial natural de regeneração, são um campo promissor para a aplicação da nanotecnologia; e esta atuação está deixan-

1 Coordenador do Grupo de Cirurgia de Nervos Periféricos do Hospital Santa Marcelina e membro do Grupo de Cirurgia de Nervos Periféricos da Disciplina de Neurocirurgia do Hospital das Clínicas da Faculdade de Medicina da Universidade de São Paulo (HC - FMUSP), SP. 2 Coordenador do Grupo de Cirurgia de Nervos Periféricos da Disciplina de Neurocirurgia do HC - FMUSP, SP. 
do o campo da especulação e da ficção científica para se tornar realidade. O objetivo deste artigo é revisar as principais técnicas disponíveis para a manipulação de átomos e moléculas e suas aplicações no tratamento das lesões traumáticas de nervos periféricos.

\section{Técnicas de manufatura de materiais em escala nanométrica}

O tamanho das estruturas construídas na escala nanométrica é menor em relação às células humanas, que possuem diâmetro de 10.000 a $20.000 \mathrm{~nm}$, e organelas e semelhante às dimensões de macromoléculas maiores, tais como enzimas e receptores. Estruturas construídas a partir da nanotecnologia com diâmetro menor que $50 \mathrm{~nm}$ podem entrar facilmente na maioria das células enquanto aquelas com diâmetro inferior a 10 a $20 \mathrm{~nm}$ podem transitar para fora dos vasos ${ }^{10}$.

A manipulação da matéria em nível atômico ou molecular exige a aplicação de várias técnicas bastante diferentes daquelas utilizadas para a construção de objetos macroscópicos e que variam dependendo do objetivo a ser alcançado. Neste universo reduzido, o movimento das estruturas deixa a influência da física clássica e passa a ser regido pela física quântica ${ }^{1}$. Neste contexto, a inércia, a fricção e a gravidade não exercem grande influência sobre as moléculas, e o posicionamento das mesmas depende de um delicado balanço entre forças de interação molecular ${ }^{20}$.

A nanotecnologia só passou a ser viável a partir da década de 80 , quando novas tecnologias de microscopia foram desenvolvidas. Embora microscópios eletrônicos possam ser utilizados para visibilização de estruturas extremamente pequenas, o processo de preparo da amostra inviabiliza a sua manipulação. Além disso, este tipo de microscópio não é capaz de fornecer dados sobre a profundidade do objeto. O desenvolvimento dos microscópios de tunelamento (MT) e de força atômica (MFA) possibilitou a realização de imagens tridimensionais em nível nanométrico com preservação da natureza da amostra ${ }^{20}$. $\mathrm{O}$ funcionamento do MT depende do efeito de tunelamento que é uma forma de movimento de origem quântica presente na escala atômica. Basicamente, o sensor deste aparato é constituído por uma agulha extremamente fina cuja ponta é formada por poucos átomos ou até mesmo por um único átomo. Esta agulha varre a superfície do objeto numa distância inferior a um nanômetro. Durante o processo de varredura os elétrons se movimentam entre as duas estruturas, efeito denominado de tunelamento, o que gera uma corrente. A imagem é formada ao se analizar a variação da corrente entre a agulha e a superfície, sendo possível a visibilização do relevo atômico. Assim como no MT, o MFA é constituído por uma sonda de extremidade muito fina que percorre a superfície do objeto longitudinalmente a uma curta distância desta. Neste segundo caso, a sonda é atraída em direção à amostra em intensidade que depende das características da mesma, o que ocasiona um deslocamento no sistema que suporta a sonda, movimento que é detectado, processado e transformado em imagem. O MFA permite avaliar todo o tipo de material isolante, ao contrário do MT, que permite o estudo apenas de materiais condutores, em que é possível a obtenção do efeito de tunelamento ${ }^{4,28,30}$.

A fabricação de nanoartefatos pode ser realizada através da montagem molecular, ou seja, com a manipulação direta do átomo, ou a partir da construção de micromecanismos que seriam programados para realizar a montagem de nanoestruturas. Para aplicação biológica, esses montadores seriam constituídos por fragmentos de DNA associados a uma interface mecânica. A fabricação desses montadores é ainda um processo teórico que exige o desenvolvimento de novas técnicas para ser viável.

O processo de montagem molecular, embora seja amplamente pesquisado, apresenta o grande inconveniente de ser muito lento, o que inviabiliza muitas vezes a sua utilização comercial. A manipulação atômica foi iniciada através de técnicas desenvolvidas com a utilização dos microscópios previamente descritos, o MT e o MFA ${ }^{20}$. Em ambos os aparatos, a interação entre os átomos e a extremidade da sonda permite a remoção dos mesmos de sua posição e o movimento deles até o local desejável. Outra forma de movimentar átomos foi obtida a partir do desenvolvimento das chamadas pinças ópticas, instrumentos formados por feixes fortemente localizados de laser infravermelho que deslocam os átomos pela transferência de sua energia ${ }^{5}$.

Além dos procedimentos descritos, uma série de processos pode ser utilizada na construção de estruturas em escala nanométrica. Uma das primeiras aquisições neste sentido foi o desenvolvimento da litografia por feixes de elétrons (ou íons), uma ferramenta bastante utilizada na obtenção de nanoestruturas tridimensionais ${ }^{18}$. Essa técnica consiste na produção de filmes cristalinos de espessuras muito finas que são recortados por feixes de elétrons, permitindo a obtenção de estruturas tridimensionais. A manufatura de nanofios também utiliza este princípio. Esse material é constituído a partir do bombardeamento de feixes de íons extremamente direcionados a chapas de um material que apresenta grande resistência à corrosão, como o ouro. A partir desse processo, diminutos orifícios na chapa são formados. Esses orifícios são ampliados de forma progressiva até 
que o material entre eles forme um filamento constituído por alguns átomos de espessura.

Outra técnica freqüentemente utilizada aproveita um fenômeno natural que é o crescimento por deposição ${ }^{8}$. Certas moléculas em estado gasoso, na presença de um material sólido, tendem a se depositar na sua superfície. Essa deposição pode ocorrer de forma extremamente lenta, com as moléculas sendo depositadas uma a uma, possibilitando a sua orientação para a formação de nanoestruturas. Esse processo pode ser controlado com precisão, resultando na obtenção de artefatos em forma de fitas, esferas ou tubos ${ }^{22,24}$. Nanotubos de carbono, considerado o material com maior resistência mecânica que existe, podem ser obtidos através deste processo ${ }^{8}$. Essas nanoestruturas são condutores elétricos naturais e têm sido amplamente aplicadas nos estudos experimentais que avaliam o uso da nanotecnologia na reparação de nervos (figura 1).

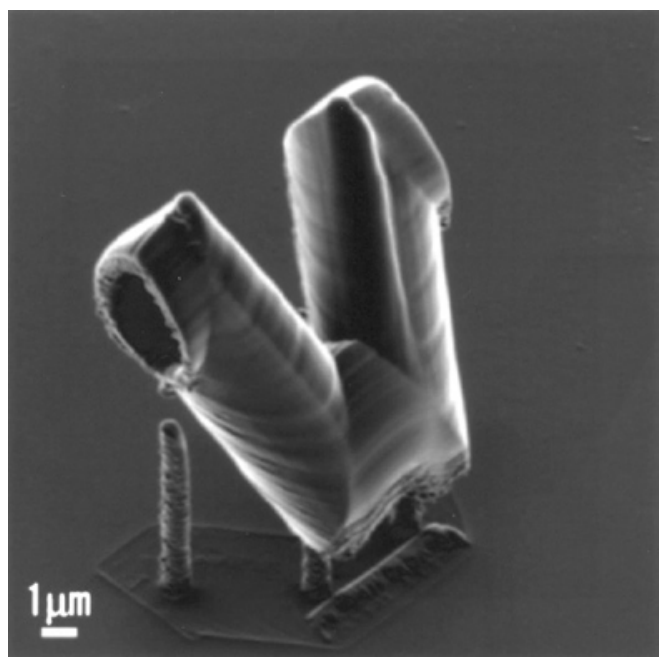

Figura 1 - Nanotubo de carbono em forma da letra " $V$ ", com diâmetro interno de 3 micrômetros. Reimpresso com a permissão de Hoshino e col. ${ }^{17}$, Copyright 2004, AVS The Science \& Technology Society.

A natureza das nanoestruturas obtidas nem sempre é a mesma das moléculas originais, pois o processo pode envolver reações químicas que alteram as moléculas $^{9}$. Assim, a nanotecnologia cria a oportunidade de desenvolvimento de materiais inexistentes a partir da manipulação atômica, o que pode ser uma desvantagem se considerarmos o desconhecimento do potencial de dano dessas novas substâncias e artefatos ao ambiente e organismos vivos. De acordo com Gatti e Rivasi, nanopartículas de natureza inorgânica não podem ser metabolizadas e teriam sua excreção dificultada nos tecidos humanos, podendo se acumular em determinadas células e levar a reações sistêmicas como febre e hepatomegalia ${ }^{12}$. Nesse contexto, o tamanho dos dispo- sitivos produzidos é importante, já que partículas com diâmetro superior a $200 \mathrm{~nm}$ podem estimular o sistema de complemento, levando a reações de hipersensibilidade e inciando mecanismos de defesa que culminam com a formação de uma cápsula fibrótica envolvendo o material ${ }^{1,14,32}$. Uma tentativa de solucionar essa complicação seria a cobertura desses nanodispositivos por material biocompatível como o polietilenoglicol, que evita a opsonização e o reconhecimento por macrófagos e a construção de nanoestruturas com polímeros degradáveis ${ }^{1,3}$.

É importante ressaltar que alguns dos processos descritos ocorrem em condições diferentes das encontradas no mundo real. Certos métodos de produção exigem um ambiente extremamente puro, como o vácuo, onde não há interferência de outros átomos no processo de fabricação. Além disso, a temperatura é extremamente baixa para reduzir a movimentação dos átomos e muitas vezes não é possível saber se o produto final obtido através desses processos resiste à temperatura ambiente.

\section{Aplicações experimentais da nanotecnologia nas lesões traumáticas de nervos periféricos}

Duas linhas de pesquisa podem ser consideradas quando se avaliam as possibilidades da aplicação da nanotecnologia nas lesões traumáticas de nervos periféricos. A primeira direciona-se à compreensão e modificação do ambiente local da lesão de forma a facilitar a regeneração e a segunda atua na substituição da estrutura neural como reparo dessas lesões.

Um dos maiores obstáculos à regeneração após o reparo de um nervo é o processo inflamatório e a formação de fibrose que atua como um obstáculo aos axônios em regeneração. Uma das propostas para aumentar a eficácia da regeneração no Sistema Nervoso Periférico é a oferta de drogas que inibam a formação de tecido conjuntivo no local do reparo ${ }^{32}$. Para que este objetivo seja atingido, estudos experimentais têm demonstrado a viabilidade do uso de estruturas biocompatíveis manipuladas através da nanotecnologia ${ }^{21}$. Estes sistemas de entrega são esferas constituídas por fibronectina e ácido hialurônico que permitem a oferta gradual de substâncias facilitadoras da regeneração através da difusão das mesmas pelas suas paredes, possibilitando ainda a manutenção da concentração da substância em um nível adequado por um tempo prolongado, utilizando-se uma única dosagem ${ }^{1}$. Isso é possível pelo conhecimento da microestrutura da parede de forma que a mesma seja biodegradável e libere a substância desejada no tempo previsto. Entre as substâncias de 
uso potencial destacam-se os anticorpos direcionados contra elementos inibidores da regeneração, tais como o fator de crescimento betatransformador, que regula a deposição de tecido conjuntivo e a formação de fibrose, e os fatores neurotróficos $(\mathrm{FT})^{27}$. No homem uma série de restrições limita a utilização dos FT. A principal está relacionada ao fato de que a produção destas substâncias após a lesão varia de acordo com o tempo e não há uma certeza de que esta variação, identificada principalmente no nervo ciático do rato, ocorra também no homem ${ }^{25}$. Um exemplo é o padrão de produção do "nerve growth factor" (NGF) e do "brain-derived neurotrophic factor" (BDNF) após a lesão do nervo ciático do rato. A concentração de ácido ribonucléico mensageiro relacionado à transcrição de NGF atinge um nível máximo rapidamente, 24 horas após a lesão ${ }^{16}$. Ao contrário, a produção de BDNF inicia-se mais tardiamente, cerca de quatro dias após uma axoniotomia, e atinge uma concentração máxima quatro semanas após a lesão ${ }^{26}$.

Uma das formas de solucionar esse problema seria a monitorização em tempo real de substâncias produzidas no local da lesão do nervo e a adequação da oferta de FT em relação a esta produção. Biosensores desenvolvidos a partir da nanotecnologia já são uma realidade e poderiam ser utilizados com esse objetivo ${ }^{22}$. Nanosensores são constituídos por fibras ópticas extremamente finas cuja extremidade é coberta com anticorpos seletivos a moléculas-alvo a serem identificadas. A transmissão de luz através da fibra cria um campo elétrico transitório na sua extremidade que é suficiente para estimular as moléculas-alvo a se combinarem com os anticorpos específicos. A emissão fluorescente dessa reação pode ser identificada e quantificada através do microscópio. Esta metodologia pode ser utilizada para a medida da concentração molecular de determinada substância e poderá esclarecer a concentração e distribuição temporal dos FT durante o processo de regeneração no homem, permitindo o uso racional e individual destas substâncias ${ }^{11,13,19}$. Bionanosensores constituídos por nanotubos de carbono envolvidos por DNA podem ser úteis futuramente nesse processo. Nesse caso, o DNA se enrola sobre o nanotubo em um formato determinado pelas cargas elétricas que aquele carrega. Heller e col. ${ }^{15}$ demonstraram que quando o DNA é exposto a determinados íons de átomos como cálcio, mercúrio e sódio, as cargas negativas são neutralizadas e a conformação da molécula de DNA se altera. Isso reduz a área de cobertura do nanotubo, de forma suficiente para alterar a sua estrutura eletrônica com conseqüente mudança da sua fluorescência natural, o que pode ser detectado e quantificado ${ }^{15}$. Considerando as lesões de nervos, é necessário que pesquisas determinem se é possível ocorrer essas alterações do DNA na presença de substâncias locais. Caso isto seja factível, a produ- ção de DNA específico para a substância a ser avaliada permitiria a identificação desta em níveis subcelulares, ou seja, no interior de organelas.

Considerando a segunda linha de pesquisa da regeneração, direcionado a substituição da estrutura do nervo, algumas publicações têm demonstrado resultados estimulantes. A possibilidade de desenvolvimento de nanotubos que orientem o crescimento adequado de forma individual das fibras nervosas em regeneração já é uma realidade em centros de pesquisas específicos. A associação de nanotubos aos chamados dispositivos microeletromecânicos (MEMS), constituídos por microplacas multiperfuradas e conectadas a eletrodos de estímulo e de registro, pode constituir uma forma de substituir a estrutura lesada do nervo ${ }^{36}$. Isso seria possível com a união de dois cotos do nervo com um condutor tubular atravessado de forma perpendicular por esses dispositivos ${ }^{35}$. Os diminutos orifícios das placas teriam como objetivo permitir a passagem dos axônios em regeneração. A instalação destas placas em vários pontos do condutor permitiria a avaliação da regeneração através da medida de potenciais de ação e a estimulação pela aplicação de corrente ${ }^{2,32}$. Este tipo de procedimento foi realizado com sucesso em estudos experimentais in vivo ${ }^{2,35}$. Além disso, Pastorino e col. demonstraram numa recente publicação a possibilidade de incorporação de substâncias facilitadoras da regeneração nesses dispositivos ${ }^{29}$.

Hoshino e cols. descreveram a construção de um MEMS que objetiva a substituição artificial da estrutura do nervo ${ }^{17}$. No estudo desses autores, inicialmente circuitos de fios de crômio foram implantados a uma base de silicone e, no final de cada circuito, foram depositados átomos de tungstênio, na forma de gás, constituindo colunas deste material (figuras 2 e 3 ). Nanotubos de carbono, com cerca de 3 micrômetros de diâmetro e extensão de 10 micrômetros, foram formados sobre estas colunas e suportados através de sua união com duas colunas adicionais formadas por átomos de carbono, dispostos numa constituição semelhante à estrutura do diamante. Esse estudo limitou-se apenas a construção da estrutura descrita e não houve aplicação in vivo. Considerando a sua aplicação prática, no final do processo, cada microtúbulo atuaria como condutor para os axônios em regeneração e também como eletrodo, o que possibilitaria a avaliação eletrofisiológica do processo em tempo real e de forma individual para cada nanotubo considerado ${ }^{17}$.

Outro tipo de procedimento utilizando a nanotecnologia para a manipulação direta dos axônios foi publicado por Sretavan e cols. ${ }^{34}$. Os autores utilizaram microtesouras para ressecar um segmento de axônio e, com a ajuda de um campo elétrico, interpor um segmento de axônio entre os cotos proximal e distal. Esses 


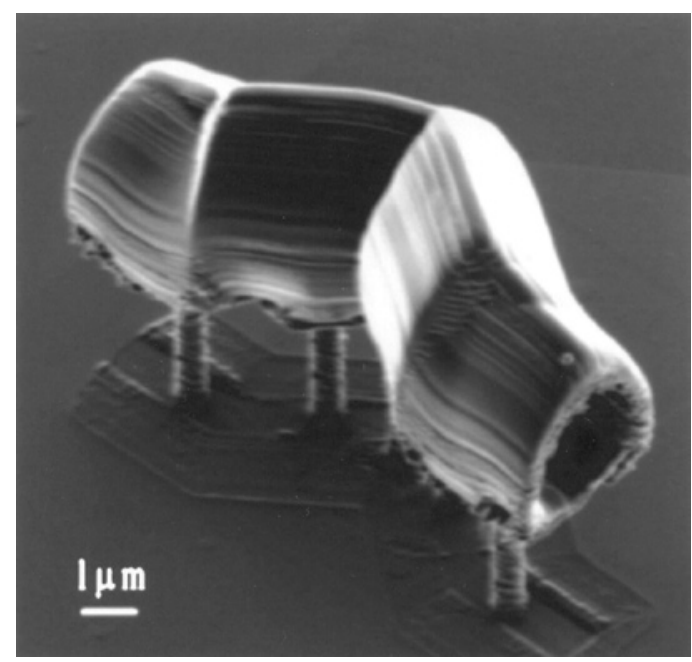

Figura 2 - Nanotubo de carbono apoiado em eletrodos de tungstênio. Reimpresso com a permissão de Hoshino e col. ${ }^{17}$, Copyright 2004, AVS The Science \& Technology Society.

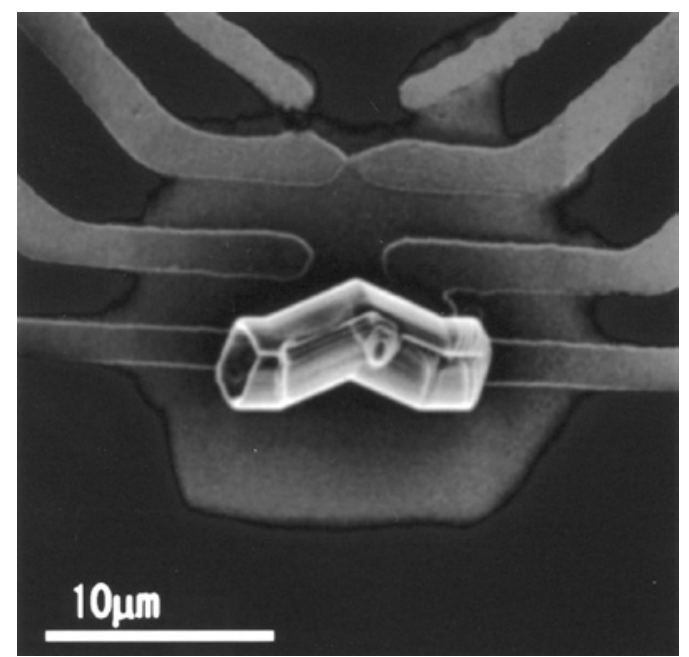

Figura 3 - Circuito de crômio onde está apoiado um nanotubo de carbono, conectado ao mesmo através de pilares constituídos por átomos de tungstênio e colunas formadas por átomos de carbono com estrutura semelhante ao diamante. Reimpresso com a permissão de Hoshino e col. ${ }^{17}$, Copyright 2004, AVS The Science \& Technology Society.

microbisturis foram construídos com silicone, cuja extremidade apresentava uma curvatura radial de $20 \mathrm{~nm}, \mathrm{o}$ tamanho de um microtúbulo ou de uma fenda sináptica. A manipulação sem contato dos axônios foi realizada através da aplicação de uma técnica denominada dieletroforese, que causa movimento de pequenos objetos polarizados quando submetidos a um campo elétrico alternado. A união dos cotos foi realizada através da eletrofusão e avaliada através do restabelecimento do fluxo axoplasmático. Somando-se à técnica proposta, os autores projetaram e desenvolveram um protótipo de uma plataforma cúbica, integrada a eletrodos de registro e estimulação, com dimensão de 1 milímetro cúbico cujas paredes eram constituídas por espaços retangulares através dos quais eram introduzidos o aparato para o corte dos axônios. Os autores sugerem que a integração de várias plataformas automatizadas permitiria que o tempo de reparo fosse reduzido, já que a taxa de reparo demonstrada foi restrita a 180 axônios por hora, inviável para o reparo de um nervo como o mediano, por exemplo. Outro problema a ser solucionado seria a identificação de quais axônios estariam lesados na região do reparo. Uma possibilidade também sugerida pelos autores seria o desenvolvimento de um programa de reconhecimento aplicado após tratamento químico local cujo objetivo seria dissolver o tecido fibrocicatricial, poupando os axônios. Apesar deste trabalho ter se limitado a avaliar apenas se esta técnica era factível in vitro, mas não in vivo, um campo promissor foi delineado para o futuro da cirurgia de nervos periféricos.

\section{Aplicações futuras da nanotecnologia}

O progresso da nanotecnologia depende de novas técnicas que permitam uma maior resolução de imagens obtidas atualmente durante a construção de nanoartefatos ou a possibilidade de se obterem imagens diretas sem a necessidade de seu processamento. Um exemplo dessas novas aquisições é o microscópio de nêutrons. Nesse tipo de microscópio a imagem é formada após o bombardeamento do objeto por um feixe de nêutrons e avaliação das alterações do trajeto dessas partículas através de detectores específicos. A grande vantagem deste processo é que os nêutrons apresentam uma elevada taxa de penetração na amostra sem a necessidade de corte ou preparo do material, dispensando também o uso de contrastes químicos. Além disso, eles interagem de forma significativa com o hidrogênio, um importante componente das amostras biológicas, facilitando a obtenção das imagens.

Considerando as oportunidades surgidas com a nanotecnologia, não é difícil imaginarmos ser possível substituir a estrutura lesada de um nervo por novos componentes produzidos localmente. Dentro desse processo, seria necessário o desenvolvimento de sistemas capazes de copiarem a si próprios, permitindo que o tempo de reparo seja reduzido e otimizado. A utilização de nanorobôs seria um tipo de solução dentro desta proposta ${ }^{20,23}$. Uma forma de obter a mobilidade dessas estruturas é a sua construção com apoios constituídos por uma liga metálica de níquel e titânio. Este tipo de liga é maleável na temperatura ambiente, sendo 
possível dobrá-la em determinado ponto a partir do seu aquecimento localizado. Após a interrupção do aumento de temperatura esta liga volta à conformação original, permitindo que, com o aquecimento intermitente, os apoios se dobrem alternadamente e movimentem o dispositivo. A movimentação dessas estruturas não poderia ser realizada por um sistema elétrico, pois o tamanho do nanorobô seria limitado pela fiação necessária. Assim, o aquecimento seria obtido por um feixe de elétrons, ou fótons, como no laser, ou até mesmo por um feixe de som. Um feixe de elétrons pode ser focalizado de forma precisa em uma área que chega até décimos de um nanômetro, além de poder ser rapidamente movido para uma outra localização. O controle computadorizado do processo possibilitaria o movimento sincronizado de braços e pernas. Os menores protótipos construídos com esses princípios apresentaram dimensões de 2 micra de largura por 10 de comprimento ${ }^{6}$. Esses protótipos poderiam ser posicionados sob um microscópio de tunelamento e possuir garras capazes de pegar e movimentar objetos de $100 \mathrm{~nm}$, dimensões de uma molécula de DNA, permitindo a manipulação dos axônios. Felizmente o cirurgião não seria aposentado, pois esse sistema exigiria uma exposição da lesão do nervo, já que não poderia haver obstáculos entre os dispositivos e os pulsos de elétrons. Num exercício futurista extremo, podemos imaginar o cirurgião tendo que lidar com programas de computador complexos que comandem a construção de nanorobôs reparadores e considerar que um dia a técnica cirúrgica possa incluir a manipulação de microscópios como o microscópio de tunelamento na sala de cirurgia.

Além da atuação local, nanorobôs poderiam ser desenhados para navegação sistêmica de forma a facilitar a investigação de casos específicos, como lesões do plexo braquial. Um exemplo desse tipo de aplicação seria a injeção de microrobôs através do líqüido cefalorraquidiano para a investigação de raízes verdadeiramente avulsionadas. Nesse caso não haveria necessidade das dimensões dos dispositivos serem obtidas em escala nanométrica, tornando mais fácil o projeto de um sistema de imagem acoplado. Em outra possibilidade, nanorobôs ofertados sistemicamente poderiam ser usados para o reparo direto do axônio, de organelas e para realizar modificações estruturais no DNA dos neurônios com o objetivo de produzir substâncias facilitadoras da regeneração ${ }^{1,23}$. Nesse caso haveria a necessidade dos mesmos apresentarem dimensões inferiores a três micrômetros, o calibre da luz capilar ${ }^{20}$, e serem aparelhados com biomotores que utilizariam energia extraída do próprio organismo.

A nanotecnologia, em associação com técnicas de clonagem celular, permitiria a construção de nervos artificiais que seriam posteriormente incorporados no local da lesão.
Nessa condição o objetivo seria simular o microambiente da matriz extracelular, contruíndo caminhos determinados por moléculas que constituem sinais específicos para os axônios em regeneração. Provavelmente o nervo seria constituído hibridamente a partir de moléculas inorgânicas que serviriam de base para a formação da estrutura com dispositivos acoplados a nanosensores cujo objetivo seria identificar moléculas sinalizatórias liberadas pelos axônios em regeneração e produzir de forma programada componentes da matriz extracelular e fatores neurotróficos a partir de microesferas ${ }^{31}$.

Outras situações identificadas na cirurgia de nervos periféricos poderiam se beneficiar de produtos obtidos a partir da nanotecnologia. Membranas constituídas por polímeros biodegradáveis, fabricados a partir da nanotecnologia, poderiam ser usados para reduzir a fibrose pós-operatória em síndrome do túnel do carpo (STC). Estimuladores constituídos por nanotubos de carbono em associação com dispositivos que gerem energia utilizando substrato do próprio meio extracelular, permitiriam o tratamento da dor neuropática sem a necessidade de uma fonte externa de energia ou de troca de eventuais baterias.

Em conclusão, apesar dos obstáculos, na fase atual das pesquisas não há mais dúvida sobre a viabilidade do emprego de técnicas obtidas a partir da nanotecnologia para o reparo das lesões traumáticas de nervos. A próxima questão que surge dentro desse campo de estudo é quanto tempo levará para que a nanotecnologia seja aplicada para este objetivo no homem.

\section{Referências}

1. ASHAMMAKHI N: Nanosize, mega-impact, potential for medical applications of nanotechnology. J Craniofac Surg 17:3-7, 2006.

2. BENZEL E, FERRARA L, ROY S, FLEISCHMAN A. Micromachines in spine surgery. Spine 29:601-6, 2004.

3. BINI TB, GAO S, TAN TC, WANG S, LIM A, HAI LB, RAMAKRISHNA S: Electrospun poly (L-lactide-co-glycolide) biodegradable polymer nanofibre tubes for peripheral nerve regeneration. Nanotechnol 15:1459-64, 2004.

4. BINNIG G, QUATE CF, GERBER C: Atomic force microscope. Phys Rev Lett 56:930-933, 1986.

5. CAPITANIO M, VANZI F, BROGGIO C, CICCHI R, NORMANNO D, ROMANO G, SACCONI L, PAVONE FS: Exploring molecular motors and switches at the single-molecule level. Microsc Res Tech 65:194-204, 2004.

6. CLEMENTS K: Disponível em URL: htpp://www.innovationon-demand.com/microactuators.htm

7. DA SILVA CG: O que é nanotecnologia? Disponível em URL: http: //www.comciencia.br/reportagens/nanotecnologia/nano10.htm.

8. DE HEER WA, PONCHARAL P, BERGER C, GEZO J, SONG ZM, BETTINI J, UGARTE D: Liquid carbon, carbon- 
glass beads, and the crystallization of carbon nanotubes. Science 307:907, 2005.

9. DE WILD M, BERNER S, SUZUKI H, RAMOINO L, BARATOFFA, JUNGATA: Molecular assembly and self-assembly: molecular nanoscience for future technologies. Ann N Y Acad Sci. 1006:291-305, 2003.

10. FERRARI M, DOWNING G: Medical nanotechnology. Shortening clinical trials and regulatory pathways. Biodrugs 19 : 203-10, 2005.

11. FRIEDRICH MJ: Nanoescale biosensors show promise. JAMA 293:1965, 2005.

12. GATTI AM, RIVASI F: Biocompatibility of micro- and nanoparticles. Part I: in liver and kidney. Biomaterials 23: 2381-7, 2002.

13. GUPTA PD, MANASI D, VASAVADAAR: Protein nanotechnology - a powerful futuristic diagnostic technique. Indian J Clin Biochem 20:48-53, 2005.

14. HAMPTON T: Researchers size up nanotechnology risks. JAMA 19:1881-3, 2005.

15. HELLER DA, JENG ES, YEUNG T, MARTINEZ BM, MOLL AE, GASTALA JB, OPTICAL MS: Detection of DNA conformational polymorphism on single-walled carbon nanotubes. Science 311:508-11, 2006.

16. HEUMANN R, KORSHING S, BANDTLOW C, THOENEN H: Changes of nerve growth factor synthesis in non-neuronal cells in response to sciatic nerve transection. J Cell Biol 104:1623-31, 1987.

17. HOSHINO T, KAWAMORI M, SUZUKIT, MATSUI S, MABUCHI K: Three-dimensional and multimaterial microfabrication using focused-ion-beam chemical-vapor deposition and its application to processing nerve electrodes. J Vac Sci Technol 22:3158-62, 2004.

18. JI Q, JI L, CHEN Y, LEUNG KN: Combined electron and ín-beam imprinter and its applications. Appl Phys Lett 85 : 4618-20, 2004.

19. KASILI PM, CULLUM BM, GRIFFIN GD, VODINH T. Nanosensors for in vivo measurement of the cardinogen benzopyrene in a single cell: $\mathrm{J}$ Nanosci Nanotechnol 2: 653-8, 2002

20. KELLY EB. Nanotechnology: implications for drug and market development. Drug Market Dev 12:311-7, 2001.

21. LABHASETWAR V: Nanotechnology for drug and gene therapy: the importance of understanding molecular mechanisms of delivery. Curr Opin Biotechnol 16:674-80, 2005.

22. LEARY SP, LIU CY, APUZZO MLJ: Toward the emergence of nanoneurosurgery: part II - nanomedicine: diagnostics and imaging at the nanoscale level. Neurosurgery 58: 805-23, 2006.

23. LEE S, BHALERAO K, FERRARI M: Object-oriented design tools for supramolecular devices and biomedical nanotechnology. Ann N Y Acad Sci 1013:110-23, 2004.

24. LEITE ER, GOMES JW, OLIVEIRA MM, LEE EJH, LONGO E, VARELA JÁ, PASKOCIMAS CA, BOSCHI TM, LANCIOTTI F, PIZANI PS, SOARES PC: Synthesis of $\mathrm{SnO}_{2}$ nanoribbons by a carbothermal reduction process. J Nanosci Nanotechnol 2:125-8, 2002
25. MARTINS RS, SIQUEIRA MG, DA SILVA CP, PLESE JPP: Mecanismos básicos da regeneração de nervos. Arq Bras Neurocir 24:20-5, 2005.

26. MEYER M, MATSUOKA I, WETMORE C, OLSON L, THOENEN H: Enhanced synthesis of brain-derived neurotrophic factor in the lesioned peripheral nerve: different mechanisms are responsible for the regulation of BDNF and NGF mRNA. J Cell Biol 119:45-54, 1992.

27. NATH RK, KWON SE, MACKINNON SE, JENSEN JN, REZNIK S, BOUTROS S: Antibody to transforming factor beta reduces collagen production in injured peripheral nerve. Plastic Reconst Surg 102:1100-6, 1998.

28. OYABU N, CUSTANCE O, YII, SUGAWARA Y, MORITA S: Mechanical vertical manipulation of selected single atoms by soft nanoindentation using near contact atomic force microscopy. Phys Rev Lett 90:176102, 2003.

29. PASTORINO L, SOUMETZ FC, RIGGIERO C: Nanofunctionalisation for the treatment of peripheral nervous system injuries. IEE Proc Nanobiotechnol 153:16-20, 2006.

30. POHL DW: Optics at the nanometer scale. Philos Transact A Math Phys Eng Sci 362:701-17, 2004.

31. PROKOP A: Bioartificial organs in the twenty-firt century: nanobiological devices. Ann N Y Acad Sci 944:472-90, 2001.

32. ROY S, FERRARA LA: Microelectromechanical systems and neurosurgery: a new era in a new millennium. Neurosurgery 49:779-8, 2001

33. SILVA GA: Nanotechnology approaches for the regeneration and neuroprotection of the central nervous system. Surg Neurol 63:301-6, 2005.

34. SRETAVAN DW, CHANG W, HAWKES E, KELLER C, KLIOT $M$ : Microscale surgery on single axons. Neurosurgery 57: 635-46, 2005

35. WALLMAN L, LEVINSON A, SCHOUENBORG J, HOLMBERG H, MONTELIUS L, DANIELSEN N, LAURELL T: Perforated silicon nerve chips with doped registration electrodes: in vitro performance and in vivo operation. Trans Biomed Eng 46:1065-73, 1999.

36. ZHANG H, HUTMACHER DW, CHOLLET F, POO NA, BURDET E: Microrobotics and MEMS-based fabrication techniques for scaffold-based tissue engineering. Macromol Biosci 5:477-89, 2005.

Original recebido em agosto de 2006

Aceito para publicação em junho de 2007

\section{Endereço para correspondência:}

Roberto Sergio Martins

Rua Maestro Cardim, 592 - Cj. 1101

01323-001 São Paulo, SP

E-mail:robar@ig.com.br 